\title{
ANALYSIS OF COMMUTERS' PERCEPTIONS ABOUT CARPOOLING SERVICE: A CASE STUDY IN LAHORE
}

\author{
Muhammad Ashraf Javid*
}

Nazam Ali**

\begin{abstract}
The increase in urban population and private vehicle ownership has resulted in traffic congestion on road networks. The traffic congestion tends to increase social cost in terms of increased travel delays, road crashes and environmental pollution. Traffic congestion also increases the generalized travel cost of road users. There is a need to look for alternative travel options to ensure sustainable development of the society and transportation infrastructure. This study aims to identify the significant relationships between the socioeconomic demographics (SEDs) of the travelers and their intentions with carpooling. The data was collected with the help of a questionnaire survey. This survey was conducted in Lahore city and three hundred and ninety four samples were obtained. The data was analyzed using frequency analysis and ordered probit regression analysis. The results revealed that the traveler's marital status, education, daily trip distance, current travel mode, household income, car ownership and possession of a driving license had a significant influence on their willingness to adopt a carpooling alternative. Besides the trip, purpose of carpooling and the number of persons with whom to share a ride had significant correlations with carpooling. These significant attributes implicate that travelers' specific characteristics play an important role in their decision to carpool. Carpooling programs are required to design, seeking the significant characteristics of travelers in the context of Lahore city as well as in other regions. These findings provide useful information to the transport planners and decision-makers in designing the transportation policies related to carpooling strategies.
\end{abstract}

Keywords: Travel Behavior, Carpooling, Traffic Congestion, SEDs, Lahore.

\section{INTRODUCTION}

Rapid increase in the urban population poses a serious threat to the transportation infrastructure, as it tends to increase the travel demand. The population of Lahore city has increased tremendously in the last two decades and at present it is more than 11.13 million (Units and Pakhtunkhwa, 2017). Private vehicle ownership is also increasing at an alarming rate, and people prefer to use their vehicles instead of public transportation facility. The private modes have a major share in the model share of Lahore city i.e. around $40 \%$ (JICA, 2012). The majority of the residents are using their private vehicles for commuting. This trend of private usage generates more traffic on the roads and results in traffic congestion. Traffic congestion causes an increase in social cost in terms of increasing energy consumption, environmental pollution and accidents. At present, every year Lahore city is facing a problem of smog due to air pollution and transportation infrastructure is one of the main contributors in this context. There is a need to assess the potential of other travel alternatives to ensure the sustainable development of the city. In this context, the Travel Demand Management (TDM) strategies can be incorporated along with supply-side measures to address traffic congestion problems. The TDM strategies focus on changing the travel demand in time and space by influencing individual travel behaviour (Meyer, 1999; Ferguson, 1990). These travel alternatives in the TDM framework may include the development of public transport systems, ride-sharing programs, carpooling and vanpooling schemes. Carpooling is a ride-sharing program where commuters share the route and cost of travelling through. These programs are arranged with the cooperation and consent of the riders. The ridesharing programs and carpooling schemes are usually helpful to reduce the traffic congestion and fuel consumption and

\footnotetext{
* Muhammad Ashraf Javid, Assistant Professor, Department of Civil and Environmental Engineering, University of Nizwa Birkat-al-Mouz, Nizwa, Oman.

Email Correspondence: ma.javid@hotmail.com

** Nazam Ali, Lecturer, Department of Civil Engineering, Univeristy of Management and Technology, Lahore, Pakistan. Email correspondence: nazam.ali@umt.edu.pk
} 
in improving the environmental quality in the cities (Do and Jung, 2018; Seyedabrishami et al., 2012). The concept of high occupancy vehicle lanes (HOVs) helps to reduce traffic congestion and improve vehicle occupancy through carpooling as it offers an opportunity to share rides for different reasons (Daganzo and Cassidy, 2008; Olsson et al., 2019). Carpooling is a TDM strategy that offers a travel alternative to the commuters based on their mutual understanding and cooperation.It helps commuters to save travel costs and time with proper communication (Zhou and Kockelman, 2011; Zhou et al., 2014).

Many factors affect the acceptability and success of a TDM measure, such as carpooling. These factors may include infrastructural, institutional, social and legal concerns (Chan and Shaheen, 2012; Javid et al., 2017; Friginal et al., 2014). The characteristics of the travelers affect the success of carpooling such as traveler's profession, gender, marital status and income (Ullah et al., 2019; Neoh et al., 2017; Blumenberg \& Smart, 2010). The service attributes of traveling alternatives including travel cost and time, registration fees, and capital costs are found significant factors in the acceptance of car-sharing systems (Javid et al., 2014; Ullah et al., 2019). Incentive schemes on carpooling and disincentives on the use of private cars contribute significantly to the promotion of ride-sharing programs(Javid et al., 2017; Chan \& Shaheen, 2012; Bruglieri et al., 2011). Car avoiders and car limiters use car share to withstand mobility stress due to key life events (Jain et al., 2020). Psychological factors also have importance, including monetary and non-monetary benefits and environmental concerns(Olsson et al., 2019). Cheap parking facilities and preferential parking treatment at parking places can help in enhancing the carpooling strategy (Olsson et al., 2019; Li et al., 2007). Results of a study report that safety, flexibility and parking cost-savings are the main motives for people to consider carpooling as a passenger, whereas convenience and social interaction are the main reasons for drivers for favoring carpooling(Park et al., 2018). The commuters showed a willingness to use a carpooling program in Dhaka and stated that safety and security would be major obstacles in the success of such car-sharing programs(Saadat and Ahmed, 2018).

A range of factors as mentioned earlier affects the implementation and success of the carpooling strategy. It is very important to assess the potential of such sophisticated TDM measures in the local socio-economic context of each city. Therefore, this paper aims to identify the relationship between traveller's socio-economic demographics (SEDs) and their intentions to use carpooling. A questionnaire survey was designed and conducted in Lahore city to gather travellers' intentions to use carpooling. Ordered regression analysis was conducted using the probit model.

\section{RESEARCH METHODS}

The main research methods included the design of a questionnaire, survey and statistical analysis of the collected data.

\section{Questionnaire Design}

A questionnaire was designed in this study comprising of traveller's socioeconomic demographics (SEDs), and responses on intentions to use carpooling as a travel mode. The personal and travel characteristics included age, gender, marital status, profession, trip purpose, household income, education, vehicle ownership, number of household members, possession of a driving license, daily travelling mode, travel distance and travel time of the commuting trips. These attributes were chosen to assess their relationship with carpooling potential. The second part of the questionnaire included the respondents' responses on intentions to use carpooling as a daily travelling mode. The respondents were asked that if a carpooling opportunity existed in a combination of HOV lanes, would they be willing to carpool. The HOVs lanes are lanes that are specified for the use of those vehicles occupying more than two or three persons in a vehicle including the driver. This statement was evaluated on the following scale such as never, occasionally, and always. The description and graphics were also presented in the questionnaire related to the concept of carpooling and $\mathrm{HOV}$ lanes in the highway system. This part also included a statement on respondents' intentions to share a ride carpool with numbers of people, e.g. 1 person, 2 persons, 3 persons, and more than 3 persons. The respondents were also asked to report their main purpose of carpooling (e.g. travel to university, travel to an office, and travel to shopping) and expectation of a reduction in travel costs.

\section{Survey and Sampling}

This survey was conducted at selected locations in Lahore city. The selected locations mainly included some government and private educational institutes and working organizations. These places were selected considering the objectives of the designed questionnaire. The target respondents were the students and employees of the educational institutes and employees of other selected organizations. This survey was conducted with the help of university undergraduate students. All the students were instructed regarding the contents and 
objectives of the questionnaire survey. Respondents were selected randomly at the selected locations. All the respondents were interviewed with the help of survey team members.

\section{Data Analysis Methods}

A simple frequency analysis was conducted for the distribution of responses related to the willingness to carpool. Cross analysis was also conducted of respondents' personal and travel characteristics with their intentions to carpool. Ordered Probit (OP) analysis was conducted to predict traveler's carpooling intentions concerning their personal and trip attributes. The OP model was initially developed by. Ordered regression models are suitable to treat the ordinal data. It was assumed that the values of the $Y$ variable show the order of the measured items; for example, let ' $Y_{i}$ ' is the likelihood to carpool of a traveler ' $i$ ' as shown in Eq. (1) and (2).

$$
\begin{aligned}
& \mathrm{Y}_{i}=\left\{\begin{array}{l}
0: \text { never } \\
1: \text { occasionally } \\
2: \text { always }
\end{array}\right. \\
& \mathrm{Y}_{i}=\quad \beta_{i} X_{i}+\varepsilon
\end{aligned}
$$

Where;

$Y_{i}=$ objective or outcomes variable of travelers' intentions to carpool

$X_{i}=$ a vector of independent or explanatory variables comprising of traveler's SEDs

$\beta_{i}=$ parameter coefficients of explanatory variables to be estimated.

$\varepsilon=$ error term which is assumed to be randomly distributed accounts for the error in the measurement of observed variables due to external constraints

The objective variable of the traveler's intentions to carpool was introduced as an ordinal variable in the ordered probit model. Explanatory variables on socioeconomic demographics (SEDs) were coded as binary variables $(0$, 1 ), for the modeling purpose. Many variables were coded and tested in the model but some of them did not make any significant relationship with the objective variable of carpooling; therefore, those insignificant variables were removed and not reported in the results.

\section{RESULTS AND DISCUSSION}

\section{Descriptive Statistics of Sample}

The total collected samples were three hundred and ninetyfour. The descriptive statistics of the sample is presented in Table 1. Almost $84.8 \%$ of the respondents were male which was higher than the actual male population in the study area. The main reasons for the high share of male respondents was their higher share in the education institutes and other selected organizations. Also, the share of working women was less in the overall population (Javid et al., 2014). Most of the respondents were single and under twenty five years of age. This was because most of the respondents were students. About $19.2 \%$ of the respondents used private cars, $38.6 \%$ used university and office transport, $11.7 \%$ used public transport, and $30.5 \%$ used motorcycles for commuting, respectively. The share of public transport was almost the same as it was in the modal share of Lahore city (JICA, 2012). For most of the respondents, the commuting trip distance was below $20 \mathrm{~km}$ and for $36 \%$ it was more than $20 \mathrm{~km}$. Almost $45.7 \%$ of the respondents had no car, $31 \%$ had one car, and $22.3 \%$ had more than two cars at their homes. Only $32 \%$ of the respondents had a valid driving license.

Table-1: Descriptive statistics of respondents' characteristics.

\begin{tabular}{|l|l|}
\hline Characteristics & \multicolumn{1}{|c|}{ Distribution(\%) } \\
\hline Gender & Male (84.8), female (15.2) \\
\hline Marital status & Single (82.8), Married (15.3) \\
\hline Age (Years) & $\begin{array}{l}\text { Under 25 (82.7), 26-30 (12.2), } \\
\text { over 30 (5) }\end{array}$ \\
\hline Household size & $\begin{array}{l}\text { Up to five members (47.7), } \\
\text { More than five (52.3) }\end{array}$ \\
\hline Profession & $\begin{array}{l}\text { Student (64), employees (27.5), } \\
\text { others (8.5) }\end{array}$ \\
\hline $\begin{array}{l}\text { Household income } \\
\text { (PKR) }\end{array}$ & $\begin{array}{l}<20,000(34.5), 21,000-60,000(23.3), \\
\text { more than 60,000 (42.2) }\end{array}$ \\
\hline Travel mode & $\begin{array}{l}\text { Private car (19.2), university/office } \\
\text { bus (38.6), public transport (11.), } \\
\text { motorcycle (42.2) }\end{array}$ \\
\hline Travel purpose & $\begin{array}{l}\text { Education (78.6), Work (18.2), } \\
\text { others (3.2) }\end{array}$ \\
\hline Trip distance & Under 20 km (64), above 20 km (36) \\
\hline Travel cost per day & $\begin{array}{l}\text { Under 100 PKR (51), 200-300 PKR } \\
(31), \text { above 300 PKR (18) }\end{array}$ \\
\hline $\begin{array}{l}\text { Household car } \\
\text { ownership }\end{array}$ & $\begin{array}{l}\text { None (45.7), 1 car (31), 2 or more } \\
\text { cars (22.3) }\end{array}$ \\
\hline Driving license & Yes (32), no (68) \\
\hline
\end{tabular}




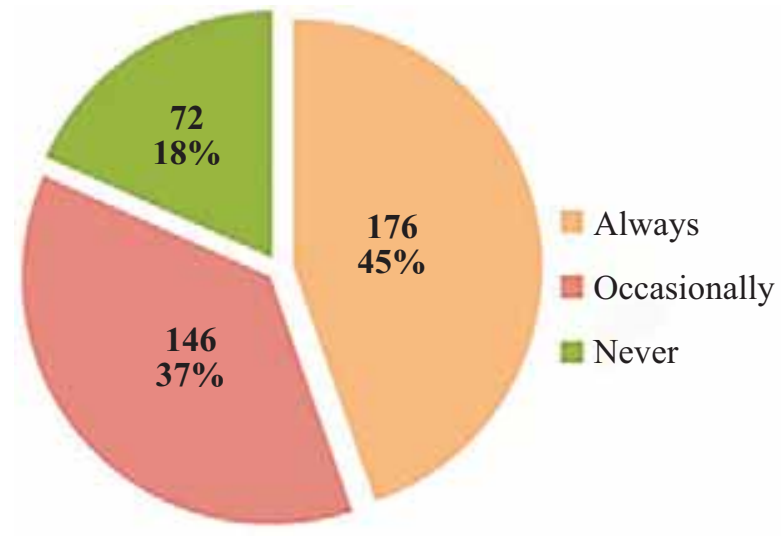

Figure-1a: Carpooling willingness.

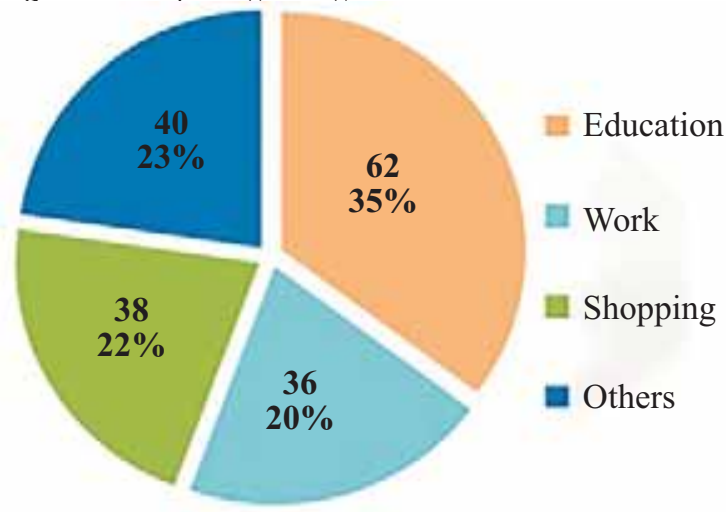

Figure-1c: The Main Purpose of Carpooling.

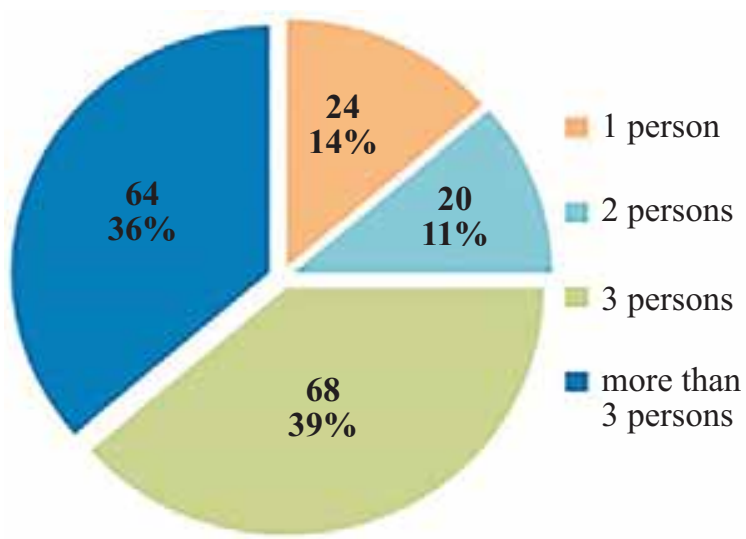

Figure-1b: Number of persons for carpooling.

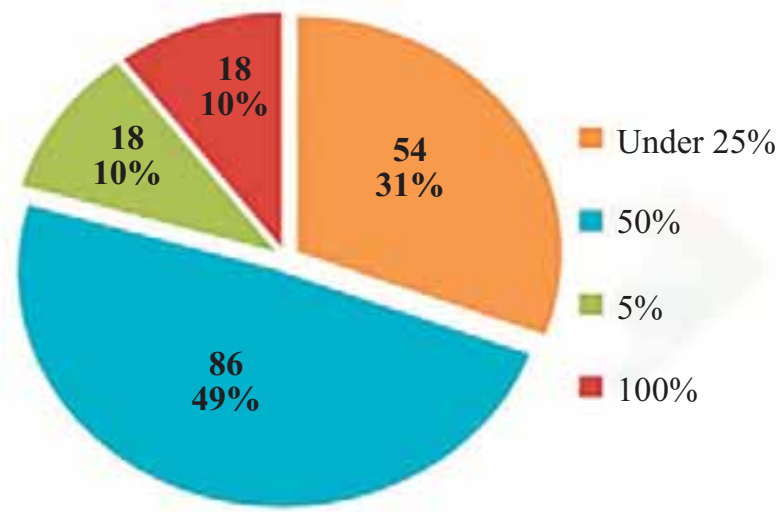

Figure-1d: Cost Reduction Expectation with Carpooling.

Figure-1: Distribution of Responses for Intentions with Carpooling Strategy.

\section{Distribution of Responses for Intentions with Carpooling}

Figure 1(a) shows the respondent's willingness to consider carpooling as a travelling mode in conjunction with $\mathrm{HOV}$ lanes. Almost $82 \%$ of the respondents were willing to consider carpooling if there was an opportunity either always or occasionally. Figure 1(b) shows that more than $75 \%$ of the targeted travellers had intentions to share ride with three or more than three persons. This potential to share a ride with more persons was helpful both for the riders as well as from social aspects. On one side, it would help in reducing the travel cost of each rider and, on other side, it would also help in reducing the use of low occupancy vehicles which in return would help in reducing the traffic congestion (Erdoðan et al., 2015; Malodia \& Singla, 2016; Galland et al., 2014). Figure 1(c) shows that the main trip purpose of carpooling included $35 \%$ for education, $20 \%$ for work, $22 \%$ for shopping, and $23 \%$ for other purposes, respectively. This distribution was consistent with the sample distribution as most of the respondents were students. Survey results in Figure 1(d) depict that the majority of the respondents expected around $50 \%$ reduction in travel cost with carpooling, which was quite logical as $75 \%$ or $100 \%$ reduction in travel costs would not be possible. Also, the cost reduction depended on the availability of the required number of riders for carpool (Delhomme and Gheorghiu, 2016; De Almeida Correia et al., 2013).

\section{Cross Distribution f Respondents' Intentions for Carpooling}

A cross-analysis was conducted between respondents' SEDs and their intentions towards carpooling. Figure 2 presents a comparison of respondents carpooling intentions with their characteristics. The respondents who use university or office transport have fewer intentions to carpool, as they feel that using such transport is cheaper than carpooling and also it is more convenient for them(Olsson et al., 2019; Javid et al., 2017). More than $75 \%$ of the public transport users reported that they would always consider carpooling as a travelling mode. A good number of current car and motorcycle car users also showed positive intentions for carpooling. 
More than $80 \%$ of the respondents with a trip distance less than $20 \mathrm{~km}$ showed positive intentions towards carpooling and around $70 \%$ of respondents with trip distance more than $20 \mathrm{~km}$ showed willingness to carpool. The tendency of carpooling was almost the same for owning a no car and one car at the household. However, this trend increased as car ownership per household increased. Most of the respondents who did not possess a driving license had the intention to carpool. It is clear from Figure 3 that those respondents who spend less on daily travel had more potential for carpooling. Figure 3(a) shows that most of the respondents who agreed for carpooling wanted to share a ride with three or more than three persons. This was true, as the increase in the number of riders decreased the travel cost per person. Figure 3(b) showed that more than $70 \%$ of the respondents had a willingness to carpool with a $50 \%$ reduction in the travel costs. It meant that the reduction in travel costs by $50 \%$ would be handy in attracting people towards carpooling. The increase in the number of riders per vehicle would also help in this context. Most of the respondents preferred carpooling for educational trips as shown in Figure 3(c). This was consistent with sample distribution as most of the respondents were students. There was also good potential for carpooling among respondents for shopping-related trips.

\section{Ordered Probit Modelling}

An ordered regression analysis was done for respondent's willingness for carpooling using probit models. The objective or outcome variable of traveler's carpooling interests was defined as never (0), occasionally (1), and always (2). The explanatory observed variables of respondent's SEDs were identified and coded as binary variables $(0,1)$. These variables were coded, purposefully seeking to assess the influence of particular characteristics of travelers as presented below:

- Marital status (single:0, married:1)

- Household income (low income:0, otherwise:1)

- Education (bachelor or above: 0, otherwise: 1)

- Profession (employees:0, otherwise:1)

- Travel mode (public transport:0, otherwise:1; university/office transport:0, otherwise:1; motorcycle:0, otherwise:1)

- Trip distance (less than $20 \mathrm{~km}$ : 0, otherwise: 1)

- Car ownership (own a car: 0, otherwise: 1)

- Have a driving license (yes: 0 , no: 1 )

- Trip purpose with carpooling (Shopping:0, otherwise:1; work:0, otherwise: 1 )

- Number of persons to share a ride (3 persons or more:0, otherwise:1)

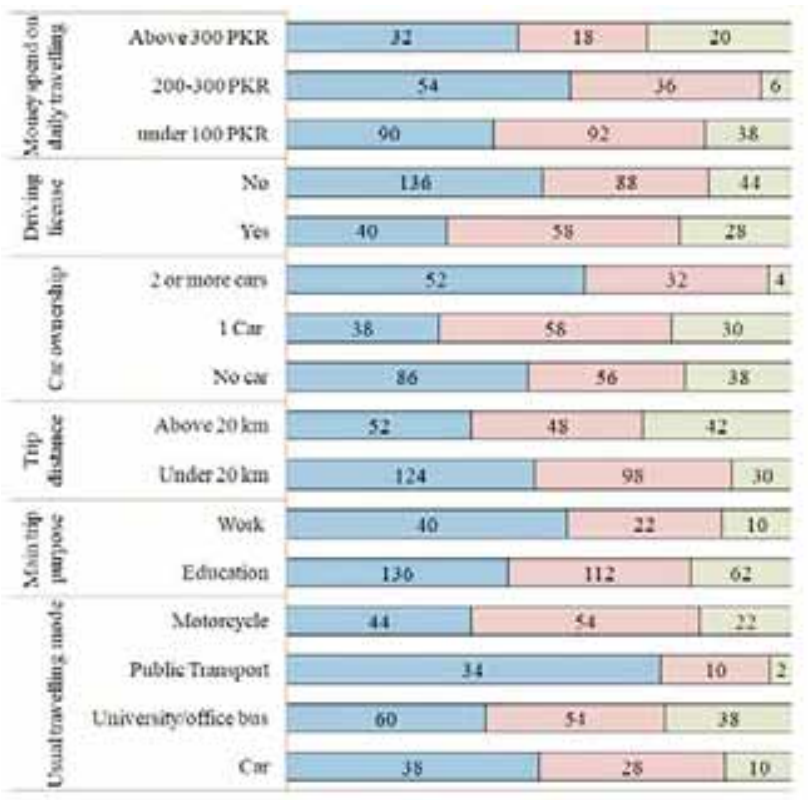

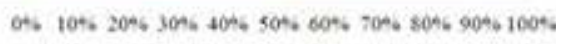

DAlazys Doscasoually oxser

Figure-2: Cross Distribution of Travel Characteristics with Carpooling Intentions.

Occasionally

\begin{tabular}{l|l|l|l|}
32 & 32 & 10 & 72 \\
\hline
\end{tabular}

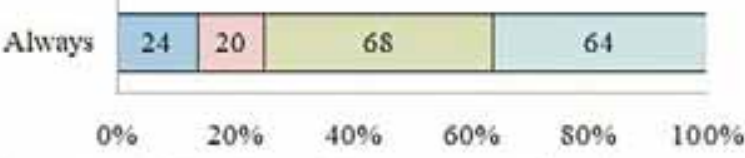

$\square 1$ person $\square 2$ persons $\square 3$ persons $\square$ more than 3 persons

Figure-3a: Carpooling Willingness Versus the Number of Persons to Share a Ride.

Occasionally

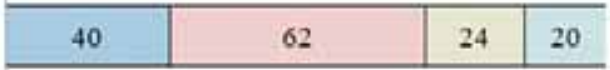

Always
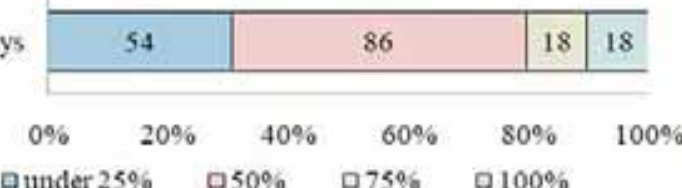

Figure-3b: Carpooling Willingness Versus \% Reduction in Travel Cost.

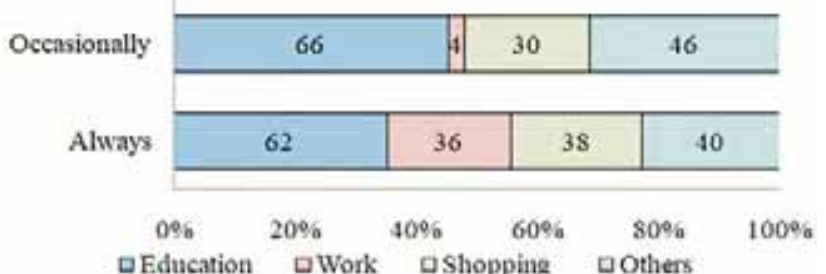

Figure-3c: Carpooling Willingness Versus the Main Purpose of Carpooling.

Figure-3: Distribution of Carpooling Willingness Versus Different Carpooling Features. 
The results of ordered probit modelling for respondents' willingness to carpool are presented in Table 2. The marital status as single formed a positive relationship with carpooling, which implied that travellers with single marital status would prefer to carpool more as they have fewer family liabilities. This finding was in agreement with the results of other studies (Amoh-Gyimah and Aidoo, 2013; Park et al., 2018). The negative coefficient value of bachelor or above education variable showed that those respondents who belong to the high education group would have low tendencies to carpool. This was true as the people who had more education generally belong to middle and high-income groups of the society, and increased travelling cost may not be an issue for them (Javid et al., 2014; Javid et al., 2016). The variable of household income under 30,000 PKR had developed a positive association with carpooling, which predicted that the travellers who belonged to a low education group would prefer to carpool as carpooling helped them to use better transport service with reduced cost. The persons who were employees had a negative potential to carpool, as the coefficient was negative. It meant that the other respondents in the sample would have better potential to carpool such as students. The respondents whose usual travel mode was office/university transport and motorcycle had negative relationships with a willingness to carpool. This was true as the office and university transport services were cheap and shared travel alternatives. However, the current public transport users had a positive association in availing a carpooling opportunity. The people who owned a private vehicle did not prefer carpooling. Travellers who owned cars usually belonged to the high-income group and such people generally had a low tendency to carpool. The respondents with daily trip distance below $20 \mathrm{~km}$ had also a positive tendency to use carpooling. It depicted that it in easy for travellers to manage to carpool if the trip distance was less than $20 \mathrm{~km}$, and for long-distance trips, the circumstances was be different. Commuting distance is significant in predicting carpooling tendency (Park et al., 2018). The travellers who had a car at their households also prefered to avail carpooling with their family members, friends, and colleagues. The possession of a driving license resulted in a negative influence on travellers' potential to carpool, as they liked to drive alone for commuting. However, other travellers liked to travel as a passenger if there was an opportunity. The modelling results showed that the travellers who were willing to share ride with more people had more potential to avail carpooling alternatives as more riders meant less travel cost per person. These results imply that some of the respondents may decline to carpool if they find less number of riders. Most of the riders would prefer carpooling for shopping and work trips. The value of the likelihood ratio is more than 0.200 and values of Pseudo RSquare were also reasonable, which showed that the obtained estimates of the model had good predictability of respondents' behaviour (Winship and Mare, 1984).

Table-2: Results of Ordered Probit Modelling for Willingness to Carpool.

\begin{tabular}{|l|c|c|}
\hline \multirow{2}{*}{ Explanatory variables } & \multicolumn{2}{|c|}{ Willingness to do carpooling } \\
\cline { 2 - 3 } & Parameter values & 0.044 \\
\hline Marital status (Single) & 0.39 & 0.000 \\
\hline Education (bachelor or above) & -0.589 & 0.000 \\
\hline Household income under 30,000 PKR & 0.863 & 0.000 \\
\hline Profession (employees) & -0.758 & 0.000 \\
\hline Travel mode (office/University transport) & -0.811 & 0.011 \\
\hline Travel mode (public transport) & 0.593 & 0.045 \\
\hline Travel mode (motorcycle transport) & -0.331 & 0.000 \\
\hline Travel distance less than 20 km per trip & 0.599 & 0.016 \\
\hline Household car ownership & 0.387 & 0.007 \\
\hline Possessing a driving license & -0.398 & 0.000 \\
\hline Number of persons to share a ride is 3 or more & 1.038 & 0.000 \\
\hline Purpose of carpooling (Work trip) & 2.279 & 0.001 \\
\hline Purpose of carpooling (Shopping trip) & 0.631 & \\
\hline Pseudo R-Square & & 0.351 \\
\hline
\end{tabular}




\section{CONCLUSIONS AND IMPLICATIONS}

This paper attempted to identify the significant relationships between the characteristics of travelers and their intentions to carpool in Lahore city. The survey results revealed that about $82 \%$ of the targeted respondents showed willingness to avail carpooling if there was an opportunity. Most of the respondents reported to share ride with three or more than three potential riders and they expected around $50 \%$ reduction in the travel costs with carpooling. The main purpose of carpooling included shopping, work and education. The ordinal regression revealed that travelers' marital status, household income, profession, education, trip distances, car ownership, current travel mode, the purpose of carpooling, driving license possession, and number of persons to share a ride were significant determinants of their intentions toward carpooling. The travelers who were single and belonged to the low-income category had more potential to carpool; therefore, such citizens should be the target of shared mobility policies and transport facilities. However, Furthermore, the people who were highly educated and those who were working professionals had a low tendency for carpooling. The current public transport users had more potential for carpooling than private vehicle users. A trip distance of less than $20 \mathrm{~km}$ was associated positively with carpooling, which implied that travelers with a shorter trip in an urban environment had significant potential for carpooling. The trip purpose of carpooling also affected the individual's likelihood to carpool under the given circumstances. These findings implied that the carpooling policy had potential in the context of Lahore, as it helped the riders to reduce their travel cost, especially for those who traveled alone on private vehicles. Thus the low-middle income people could be a better target group of this policy. Some organizations and educational institutions based carpooling programs may be more feasible. The implementation of such programs would help in reducing private dependency and enhance vehicle occupancy. The implementation of carpooling may bring economic and environmental efficiency as well as efficiency in transportation infrastructure. Consequently, this would help in alleviating traffic congestion in Lahore.

The scope and implications of these study findings have limitations as the sample mainly consisted of a specific segment of Lahore. The detailed assessment of travelers' attitudes is required to develop comprehensive transportation policies related to carpooling. Future studies should focus on assessing the social-cognitive aspects of carpooling with a large sample size in the context of Lahore city.

\section{REFERENCES}

Amoh-Gyimah, R. and Aidoo, E.N, 2013, Mode of Transport to Work by Government Employees in the Kumasi Metropolis, Ghana, "Journal of Transport Geography", 31, 35-43.

Blumenberg, E. and Smart, M., 2010, "Getting by With a Little Help from My Friends...and Family: Immigrants and Carpooling", Transportation and .

Bruglieri, M., Ciccarelli, D., Colornia, A. and Luè, A., 2011, "PoliUniPool: A Carpooling System for Universities", Procedia - Social and Behavioral Sciences.

Chan, N.D. and Shaheen, S.A., 2012, "Ridesharing in North America: Past, Present, and Future", Transport Reviews. Daganzo, C.F. and Cassidy, M.J., 2008, "Effects of High Occupancy Vehicle Lanes on Freeway Congestion”, Transportation Research Part B: Methodological, 42 (10), 861-872.

De Almeida Correia, G.H., de Abreu e Silva, J. and Viegas, J.M., 2013, "Using Latent Attitudinal Variables Estimated Through a Structural Equations Model for Understanding Carpooling Propensity", Transportation Planning and Technology, 36 (6), 499-519.

Delhomme, P. and Gheorghiu, A., 2016, "Comparing French Carpoolers and Non-Carpoolers: Which Factors Contribute the Most to Carpooling?", Transportation Research Part D: Transport and Environment.

Do, M. and Jung, H., 2018, "The Socio-Economic Benefits of Sharing Economy: Colleague-Based Carpooling Service in Korea", Journal of Open Innovation: Technology, Market, and Complexity, 4 (3), 40.

Erdoðan, S., Cirillo, C. and Tremblay, J.M., 2015, "Ridesharing as a Green Commute Alternative: A Campus Case Study", International Journal of Sustainable Transportation, 9 (5), 377-388. 
Ferguson, E., 1990, “Transportation Demand Management Planning, Development, and Implementation”, Journal of the American Planning Association, 56 (4), 442-456.

Friginal, J., Gambs, S., Guiochet, J. and Killijian, M.O., 2014, “Towards Privacy-Driven Design of a Dynamic Carpooling System", Pervasive and Mobile Computing.

Galland, S., Knapen, L., Yasar, A.U.H., Gaud, N., Janssens, D., Lamotte, O., Koukam, A. and Wets, G., 2014, "Multi-agent Simulation of Individual Mobility Behavior in Carpooling", Transportation Research Part C: Emerging Technologies.

Jain, T., Johnson, M. and Rose, G., 2020, "Exploring the Process of Travel Behaviour Change and Mobility Trajectories Associated with Car Share Adoption", Travel Behaviour and Society, 18, 17-131.

Javid, M.A., Mehmood, T., Asif, H.M., Vaince, A.U. and Raza, M., 2017, "Travelers' Attitudes Toward Carpooling in Lahore: Motives and Constraints", Journal of Modern Transportation, 25 (4), 268-278.

Javid, M.A., Okamura, T., Nakamura, F., Tanaka, S. and Wang, R., 2016, "People's Behavioral Intentions Towards Public Transport in Lahore: Role of Situational Constraints, Mobility Restrictions and Incentives, KSCE Journal of Civil Engineering, 20 (1), 401-410.

Javid, M.A., Okamura, T., Nakamura, F., Tanaka, S. and Wang, R., 2014, "Public Perceptions to Travel Demand Management Measures in Lahore, Pakistan: Analysis and Implications", Proceedings of the Pakistan Academy of Sciences, 51 (1), 17-29.

JICA, 2012, "The Project for Lahore Urban Transport Master Plan in the Islamic Republic of Pakistan", Viewed 10 Aughust 2020, from: <https://openjicareport.jica.go.jp/pdf/12068110_01.pdf.

Li, J., Embry, P., Mattingly, S.P., Sadabadi, K.F., Rasmidatta, I. and Burris, M.W., 2007, "Who Chooses to Carpool and Why? Examination of Texas Carpoolers", Transportation Research Record, 2021 (2021), 110-117.

Malodia, S. and Singla, H., 2016, "A study of Carpooling Behaviour Using a Stated Preference Web Survey in Selected Cities of India. Transportation Planning and Technology, 39 (5), 538-550.

Meyer, M.D., 1999, "Demand Management as an Element of Transportation Policy: Using Carrots and Sticks to Influence Travel Behavior", Transportation Research Part A: Policy and Practice, 33 (7-8), 575-599.

Neoh, J.G., Chipulu, M. and Marshall, A., 2017, "What encourages people to carpool? An evaluation of factors with metaanalysis", Transportation.

Olsson, L.E., Maier, R. and Friman, M., 2019, "Why Do They Ride with Others? Meta-Analysis of Factors Influencing Travelers to Carpool”, Sustainability", 11 (8), 2414.

Park, Y., Chen, N. and Akar, G., 2018, "Who is Interested in Carpooling and Why: The Importance of Individual Characteristics, Role Preferences and Carpool Markets", Transportation Research Record: Journal of the Transportation Research Board, 2672 (8), 708-718.

Seyedabrishami, S., Mamdoohi, A., Barzegar, A. and Hasanpour, S., 2012, "Impact of Carpooling on Fuel Saving in Urban Transportation: Case Study of Tehran", Procedia - Social and Behavioral Sciences, 54, 323-331.

Ullah, I., Liu, K. and Vanduy, T., 2019, "Examining Travelers' Acceptance towards Car Sharing Systems_-Peshawar City, Pakistan" Sustainability, 11 (3), 808.

Units, A. and Pakhtunkhwa, K., 2017, "District wise population by sex and rural/urban", Government of Pakistan, Islamabad. Winship, C. and Mare, R.D.' 1984, “Regression Models with Ordinal Variables”, American Sociological Review, 49 (4), 512.

Y. Saadat, S. and S. Ahmed, K., 2018, "Consumers' Perceptions on Car Sharing: A Preliminary Study in Dhaka City Independent Review of Bangladesh's Development View project”, World Journal of Social Sciences, 8 (2), 43-56.

Zhou, B. and Kockelman, K.M., 2011, "Opportunities for and impacts of carsharing: A survey of the Austin, Texas market", International Journal of Sustainable Transportation, 5 (3), 135-152.

Zhou, G., Huang, K. and Mao, L., 2014, "Design of Commute Carpooling Based on Fixed Time and Routes", International Journal of Vehicular Technology, 1-8. 